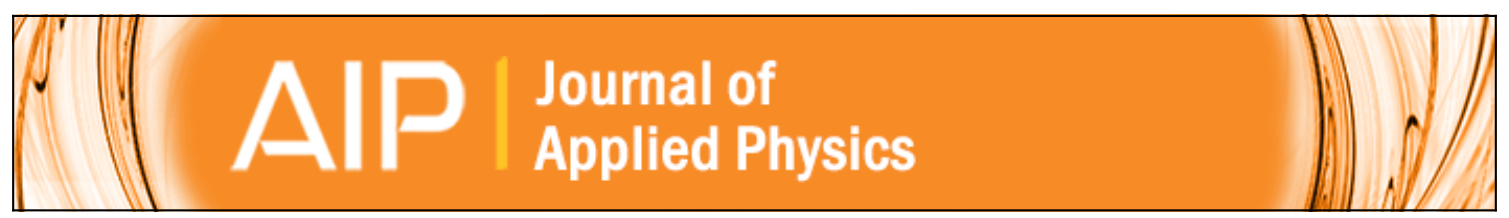

\title{
Photothresholds in Mg2Ge
}

C. A. Mead

Citation: Journal of Applied Physics 35, 2460 (1964); doi: 10.1063/1.1702881

View online: http://dx.doi.org/10.1063/1.1702881

View Table of Contents: http://scitation.aip.org/content/aip/journal/jap/35/8?ver=pdfcov

Published by the AIP Publishing

\section{Articles you may be interested in}

Interface magnetism of Co2FeGe Heusler alloy layers and magnetoresistance of $\mathrm{Co} 2 \mathrm{FeGe} / \mathrm{MgO} / \mathrm{Fe}$ magnetic tunnel junctions

J. Appl. Phys. 116, 163902 (2014); 10.1063/1.4898761

Magnetic properties of Mn-doped chalcopyrites: ( $\mathrm{Be} \mathrm{Sn}, \mathrm{Be} \mathrm{Ge}, \mathrm{Mg} \mathrm{Ge}$ ) N 2

J. Appl. Phys. 103, 07D109 (2008); 10.1063/1.2830062

Large magnetic effect on photothresholds in doped EuO

AIP Conf. Proc. 24, 401 (1975); 10.1063/1.30156

ThirdOrder Elastic Constants of $\mathrm{Ge}, \mathrm{MgO}$, and Fused $\mathrm{SiO} 2$

J. Appl. Phys. 36, 2504 (1965); 10.1063/1.1714520

Preparation and some Properties of Mg2Ge Single Crystals and of Mg2Ge pn Junctions J. Appl. Phys. 36, 2461 (1965); 10.1063/1.1714512

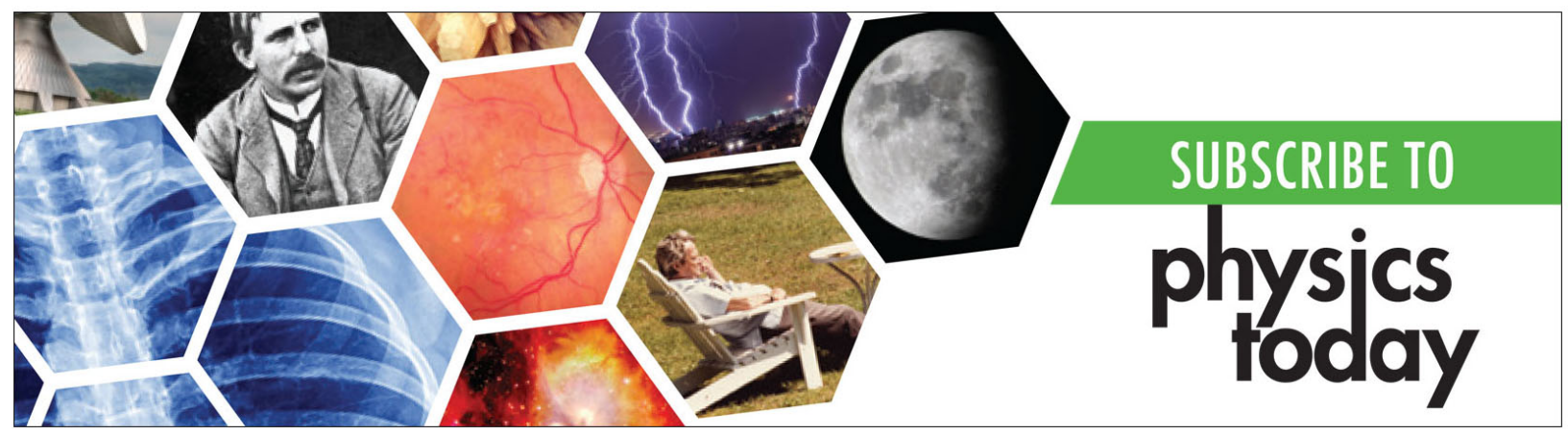


Shockley-Read-Hall centers. ${ }^{4}$ It can be shown that, within the depletion region, the time constant for the emission of carriers from such levels is given by ${ }^{5}$

$$
\tau_{t} \approx 1 /\left[\sigma_{n} V_{t h} n_{i}+\sigma_{p} V_{t h} n_{i}\right] \text {. }
$$

${ }^{4}$ W. Shockley and W. T. Read, Phys. Rev. 87, 835 (1952).

${ }^{5}$ C. T. Sah and G. Reddi, IEEE Trans. Electron Devices (to be published).
Thermal velocity of carriers is $v_{t h} \approx 10^{7} \mathrm{~cm} / \mathrm{sec}$ and for silicon at room temperature the intrinsic carrier concentration $n_{i}$ is $\approx 10^{10} \mathrm{~cm}^{-3}$. These values, together with typical carrier capture cross sections $\sigma_{p} \approx \sigma_{n} \approx 10^{-15} \mathrm{~cm}^{2}$, give $\tau_{l} \approx 10^{-2} \mathrm{sec}$ which is in order-of-magnitude agreement with the observed transition frequency.

\title{
Photothresholds in $\mathrm{Mg}_{2} \mathrm{Ge}$
}

\author{
C. A. MEAD \\ California Institute of Technology, Pasadena, California
}

(Received 1 April 1964)

\begin{abstract}
Optical absorption and surface barrier photoresponse measurements have been made on cleaved samples of $\mathrm{Mg}_{2} \mathrm{Ge}$. The form of the results obtained from both techniques indicates an indirect transition at approximately $0.54 \mathrm{eV}$ followed by a direct transition at approximately $1.8 \mathrm{eV}$.
\end{abstract}

$\mathrm{T}$ $\mathrm{HE}$ electrical properties of $\mathrm{Mg}_{2} \mathrm{Ge}$ have been studied in some detail by Redin et al. ${ }^{1}$ and more recently, Koenig et al. ${ }^{2}$ in an attempt to determine the energy gap of this material by means of infrared absorption measurements. Although the absorption coefficient

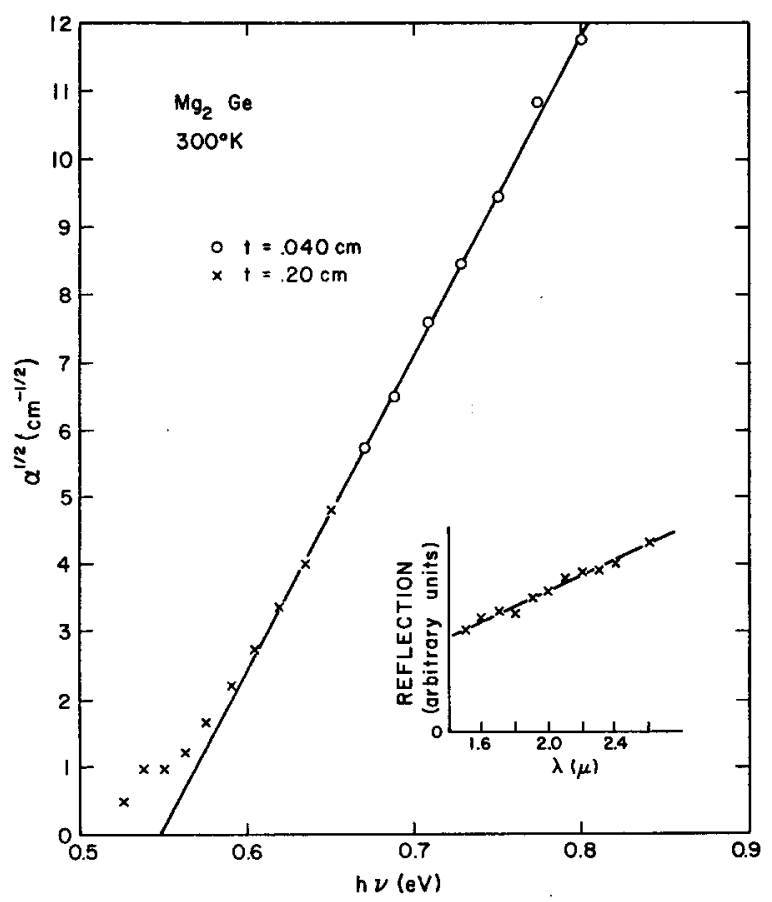

FIG. 1. Square root of absorption coefficient vs photon energy for cleaved samples.

1 R. D. Redin, R. G. Morris, and G. C. Danielson, Phys. Rev. 109,1916 (1958).

2 P. Koenig, D. W. Lynch, and G. C. Danielson, J. Phys. Chem. Solids 20, 122 (1961). was measured over a considerable range of temperature, the dependence upon energy could not be fit to any theoretical model and hence the value of the band gap could not be ascertained. In the present work, infrared absorption measurements have been made on cleaved samples of $\mathrm{Mg}_{2} \mathrm{Ge}$. The energy dependence of the absorption is consistent with the theory for allowed indirect transitions.

The square root of the room-temperature absorption coefficient is plotted as a function of photon energy in Fig. 1. The form of the curve as well as its rate of increase with $h v$ is very similar to that obtained with other materials where the transitions are known to be indirect. It can be seen that the result is fit well by a straight line extrapolating to $0.548 \mathrm{eV}$. This branch we interpret as arising from the phonon emission process. At low absorption coefficients, a second branch probably corresponding to the phonon absorption process can be seen. This data was obtained from transmission measurements on samples of two different thicknesses cleaved from a single large $p$-type crystal (carrier concentration $\leqslant 10^{17} \mathrm{~cm}^{-3}$ ). It was noted by $\mathrm{H}$. Kroemer that a cleaved surface could be exposed to the atmosphere for extended periods without showing any sign of deterioration. However, if the sample was abraded in any way, a surface film formed rapidly. Since previous work was done on polished surfaces, comparison with the present results is difficult. Reflection from the sample surface as a function of wavelength is shown in the inset in Fig. 1. The maximum value of the reflectivity is of the order of $50 \%$. It can be seen that the value of the reflectivity did not change appreciably over the wavelength range where the reflection correction was appreciable. Hence, the absorption coefficient was 


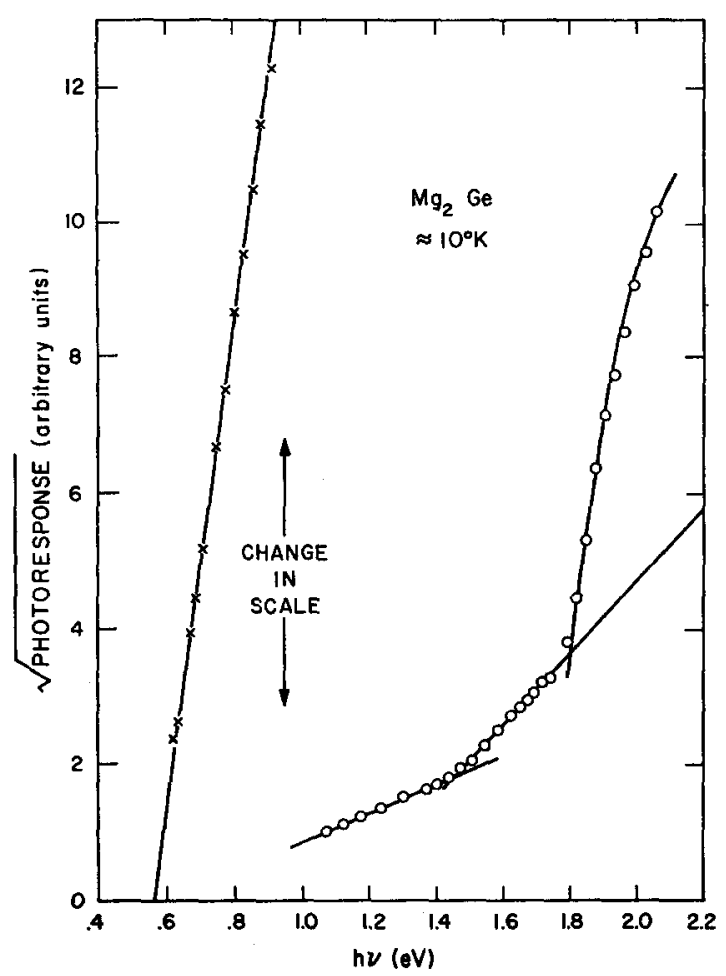

FIG. 2. Low-temperature photoresponse of surface barrier unit.

calculated from transmission data assuming the reflection correction to be constant, and equal to its value at wavelengths longer than the absorption edge.

Measurements of the photothresholds were also made on a number of samples by the surface barrier photoresponse technique. ${ }^{3-5}$ Samples were prepared by vacuum cleavage of $n$-type $\mathrm{Mg}_{2} \mathrm{Ge}$ (carrier concentration $\left.\approx 10^{17} \mathrm{~cm}^{-3}\right)$ and immediate evaporation of a thin $(\approx 1000-\AA \AA)$ gold layer. Measurements were made under identical conditions at several different temperatures. Photoresponse of a typical sample at approximately $10^{\circ} \mathrm{K}$ is shown in Fig. 2. At low photon energy, a straight line fit to the experimental points extrapolates to $0.57 \pm 0.01 \mathrm{eV}$. Again the form of the response is very similar to that obtained on other indirect materials. ${ }^{4,5}$

The abrupt increase in photoresponse at $1.8 \mathrm{eV}$ is very similar to that observed for a number of other materials $\mathbf{s}^{4, \mathbf{b}}$ and is attributed to direct transitions from the valence to conduction band. Similar data were taken at $77^{\circ}$ and $195^{\circ} \mathrm{K}$. A rather accurate value for the direct edge can be obtained by subtracting the extrapolated response due to indirect transitions. The results of this procedure are shown in Fig. 3. In this figure, the response has been arbitrarily normalized to the indirect transition response at $1.6 \mathrm{eV}$. It is interesting to note that the relative strength of the direct transition

\footnotetext{
${ }^{3}$ W. G. Spitzer and C. A. Mead, J. Appl. Phys. 34, 3061 (1963). ${ }^{4}$ C. A. Mead and W. G. Spitzer, Phys. Rev. Letters 11, 358 (1963).
}

${ }^{5}$ W. G._Spitzer and C. A. Mead, Phys. Rev. 133, A872(1964).
TABLE I. Summary of data obtained on direct and indirect transitions in $\mathrm{Mg}_{2} \mathrm{Ge}$. The temperature coefficient of the direct edge was obtained from the $195^{\circ}$ and $77^{\circ} \mathrm{K}$ data, of the indirect edge from the $300^{\circ}$ and $77^{\circ} \mathrm{K}$ data.

\begin{tabular}{ccc}
\hline Temperature $\left({ }^{\circ} \mathrm{K}\right)$ & $\begin{array}{c}\text { Indirect } \\
\text { threshold }(\mathrm{eV})\end{array}$ & $\begin{array}{c}\text { Direct } \\
\text { threshold }(\mathrm{eV})\end{array}$ \\
\hline $\begin{array}{c}\text { Absorption } \\
300\end{array}$ & $0.548 \pm 0.004$ & $\ldots$ \\
$\begin{array}{c}\text { Surface barrier response } \\
195\end{array}$ & $0.54 \pm 0.01$ & $1.737 \pm 0.005$ \\
77 & 0.57 & 1.780 \\
$\approx 10$ & 0.57 & 1.804 \\
Temperature coefficient & & \\
$\left(10^{-4} /{ }^{\circ} \mathrm{K}\right)$ & $\approx 2 \pm 1$ & 3.5 \\
\hline
\end{tabular}

decreases within increasing temperature and also tends to round off at higher energies. The reason for this phenomena is not known. A summary of the results for different temperatures is given in Table $\mathrm{I}$. The temperature coefficients of the two thresholds have been computed using the $195^{\circ}$ and $77^{\circ} \mathrm{K}$ data and are somewhat lower than those given by other workers. It should be noted that the temperature coefficient for the indirect edge is probably not accurate to better than about a factor of 2. Another feature shown in Fig. 3 is worthy of some comment, that is the increase in slope of the indirect data at about $1.54 \mathrm{eV}$. This behavior was present in some samples to a much larger degree than in others and tended to become less pronounced at higher temperatures. In one particular sample, it was strong enough to be clearly apparent at $77^{\circ} \mathrm{K}$. Several ex-

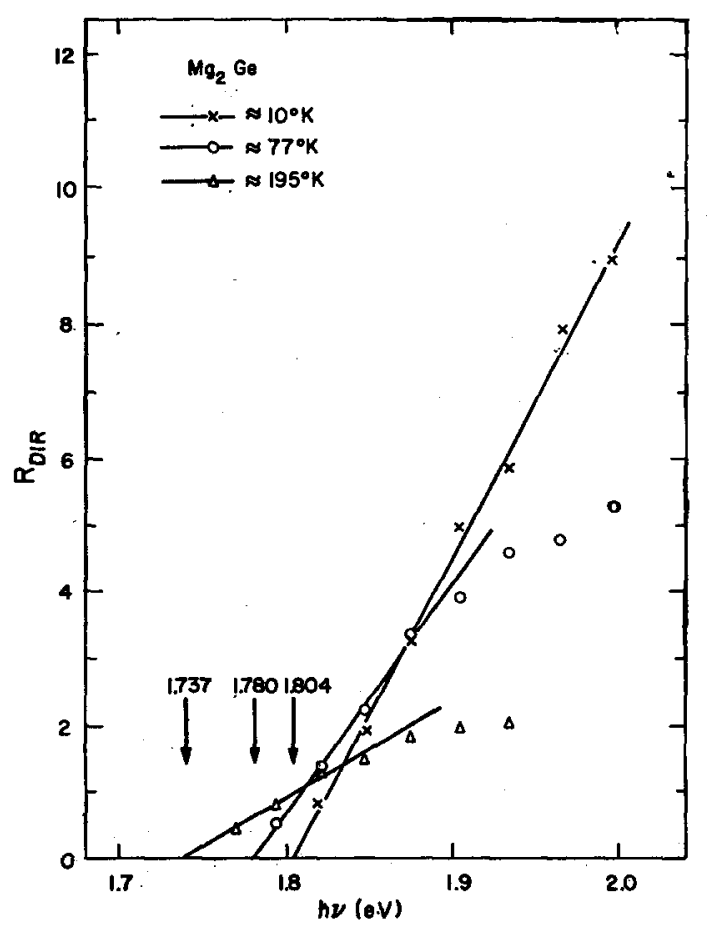

F1G. 3. Photoresponse $(R)$ due to direct transition as obtained by subtraction of the extrapolated indirect response. 
planations for this increase in response could be advanced, but at present the author has no diffinitive experiment to evaluate the various alternatives.

It should be noted that the values quoted are photothresholds which are closely related to, but not identical with, the band gap energies. A T. O. phonon energy of $0.0256 \mathrm{eV}$ can be deduced from infrared reflectivity data of McWilliams and Lynch. ${ }^{6}$ Assuming that the ratio of the L. O. and T. O. phonon energies is approximately the same as in $\mathrm{Mg}_{2} \mathrm{Si}$, the $\mathrm{L}$. $\mathrm{O}$. phonon energy is approximately $0.031 \mathrm{eV}$. Presumably the indirect band gap can be obtained by subtracting the $\mathrm{L}$. $\mathrm{O}$. phonon

${ }^{6}$ D. A. McWilliams and D. W. Lynch. Phys. Rev. 130, 2248 (1963). energy from the threshold, giving $\mathrm{E}_{y}=0.516 \pm 0.005 \mathrm{eV}$ at $300^{\circ} \mathrm{K}$ and $0.54 \pm 0.01$ at $10^{\circ} \mathrm{K}$. The photothresholds for the direct process can differ from the direct band gap ${ }^{7}$ by as much as $0.15 \mathrm{eV}$ due to direct exciton formation, multiphonon processes, and possibly otherbroadening phenomena as well.

The author would like to thank $H$. Kroemer for supplying the samples of $\mathrm{Mg}_{2} \mathrm{Ge}, \mathrm{W}$. G. Spitzer for helpful discussions, and H. M. Simpson for the fabrication of the samples. The work was supported in part by the Office of Naval Research and the International Telephone and Telegraph Company.

${ }^{7}$ D. F. Nelson, L. F. Johnson, and M. Gershenzon, Bull. Am. Phys. Soc. 9, 236 (1964) (also, to be published).

\title{
Electrical Measurements and X-Ray Lattice Parameter Measurements of $\mathrm{GaAs}$ Doped with $\mathrm{Se}, \mathrm{Te}, \mathrm{Zn}$, and $\mathrm{Cd}$ and the Stress Effects of These Elements as Diffusants in GaAs
}

\author{
J. BLACK AND P. LUBLIN \\ General Telephone \& Electronics Laboratories, Incorporated, Bayside, New York
}

(Received 30 January 1964)

\begin{abstract}
The room-temperature lattice parameter of GaAs doped with $\mathrm{Zn}, \mathrm{Cd}, \mathrm{Te}$, and Se has been measured with a precision of \pm 3 parts in $10^{5}$ using an $x$-ray powder diffraction technique. Electrical measurements and microscopic examination of samples were used to qualify the measured lattice parameters and allow limits of the solute lattice dilation coefficient $(\beta)$ to be calculated. For $\mathrm{Zn}$ in $\mathrm{GaAs}, \beta \overline{<} 1.2 \times 10^{-25} \mathrm{~cm}^{3} / \mathrm{atom}$, for $\mathrm{Cd}$ in GaAs, $\beta<1.1 \times 10^{-24} \mathrm{~cm}^{3} /$ atom; for $\mathrm{Se}, \beta>1.3 \times 10^{-24} \mathrm{~cm}^{3} /$ atom; and for $\mathrm{Te}, \beta>1.7 \times 10^{-24} \mathrm{~cm}^{3} /$ atom. Limits of the stresses that could be generated at the onset of the diffusion of $\mathrm{Zn}, \mathrm{Cd}$, $\mathrm{Te}$, or Se into $\mathrm{GaAs}$ are derived from these $\beta$ values. It appears likely that these stresses will be sufficient to cause plastic flow and the generation of large numbers of dislocations for diffusion of any of these elements into GaAs under conditions of high diffusant surface concentration and high temperature. Preliminary experiments show that the diffusion of zinc into $\mathrm{GaAs}$ at $1100^{\circ} \mathrm{C}$ can generate a high dislocation density in the diffused layer.
\end{abstract}

\section{INTRODUCTION}

W HEN a semiconductor is heavily doped to produce a high concentration of free carriers, significant changes may occur in the lattice parameter as a result of the doping. If dopants which affect the lattice spacing are introduced by diffusion, high stresses can build up in the diffused semiconductor as a result of the lattice mismatch which is developed across the diffusion front. These stresses can lead to plastic deformation or can cause embrittlement of a diffused sample. Recent work, for example, has shown that highly disturbed surface layers can be produced in silicon by the indiffusion of boron ${ }^{1}$; this is consistent with the marked decrease of the lattice constant of silicon at high boron concentrations. ${ }^{2}$ Generally, the region of the diffused semiconductor most affected by

${ }^{1}$ D. P. Miller, J. E. Moore, and C. R. Moore, J. Appl. Phys. 33, 2648 (1962); S. Prussin, J. Appl. Phys. 32, 1876 (1961); H. J. Queisser, J. Appl. Phys. 32, 1776 (1961).

${ }_{2}^{2}$ F. H. Horn, Phys. Rev. 97, 1521 (1955). these lattice parameter changes will be near the $p-n$ junction. This is significant since high stresses or plastic flow near the $p-n$ junction are known to have extreme effects on the properties of a $p n$ junction device. ${ }^{3}$ In view of the intensive development of GaAs devices in the last few years, it is important to know if significant changes occur in the lattice parameter of GaAs upon heavy doping with elements which are useful for $n$ - and $p$-type doping, i.e., group II, IV, and VI elements.

The first measurements of the lattice parameter of doped GaAs were made by Kolm, Kulin, and Averbach ${ }^{4}$ in 1957. They studied the effect of additions up to 2 at. $\%$ of $\mathrm{Si}, \mathrm{Ge}, \mathrm{Sn}$, and $\mathrm{Pb}$ on the lattice spacing of GaAs. From their measurements it appears that all of these group IV elements cause a marked decrease in the lattice parameter of $\mathrm{GaAs}$, each of the elements causing

${ }^{3}$ W. Rindner, J. Appl. Phys. 33, 2479 (1962) ; J. H. Westbrook and J. J. Gilman, J. Appl. Phys. 33, 2360 (1962).

${ }_{4}$ C. Kolm, S. A. Kulin, and B. L. Averbach, Phys. Rev. 108, $965(1957)$ 